\title{
Delineamento das PESQUisas SOBRe PRÁtICAS PEDAGógicas QUE ADOTAM COMO PRINCÍPIO A ZONA DE DESENVOLVIMENTO PROXIMAL
}

\author{
Delineation of research on pedagogical practices adopting as a principle the \\ Zone of Proximal Development
}

\author{
COSTA, José Wilson da ${ }^{1}$ \\ ORTEGA, Lenise Maria Ribeiro²
}

\begin{abstract}
Resumo
Este artigo tem como centralidade delinear as pesquisas sobre as práticas pedagógicas que utilizam como princípio norteador a Zona de Desenvolvimento Proximal (ZDP) de Vygotsky nas interações educacionais. A metodologia adotada utilizou a pesquisa exploratória, realizada em 54 Bases de Dados Nacionais, que permitiu levantar 13.174 trabalhos, dos quais foram selecionados 852 para compor o estudo. Os resultados aqui apresentados referem-se à execução da primeira parte da pesquisa que consistiu em fazer um levantamento das teses e dissertações que adotaram a ZDP nas interações das práticas da educação presencial e a distância e na compilação dos dados. Os resultados apontaram que apesar do conceito de Zona de Desenvolvimento Proximal ter sido bastante recorrente nas pesquisas realizadas nas últimas décadas, ainda há poucos estudos que tomam como base às práticas da educação a distância on-line.
\end{abstract}

Palavras-Chave: Zona de Desenvolvimento Proximal. Educação a Distância. On-line.

\section{ABStRAct}

This article has as centrality to outline the pedagogical practices that use as a guiding Vygotsky's principle of Zone of Proximal Development (ZPZ) in educational interactions. The methodology used was the exploratory research carried out in 54 National Databases, where 13,174 papers were found, of which 852 were selected to compose the study. The results refer to the execution of the first part of the research that consisted of a survey of theses and dissertations that adopted the ZPD in the interactions of the practices of distance learning and the compilation of the data. The results pointed out that although the concept of a zone of proximal development has been quite recurrent in the surveys carried out in the last decades, there is still little study on the application of the ZPD on the teaching practices of distance learning on-line.

Keywords: Proximal Development Zone. Distance learning. On-line.

\footnotetext{
${ }^{1}$ Possui graduação em Engenharia Elétrica pela Universidade Federal de Minas Gerais (1988), mestrado em Engenharia Elétrica pela Universidade Federal de Minas Gerais (1993) e doutorado em Ciências da Informação pela Universidade Federal de Minas Gerais (2002). Atualmente é professor do Programa de Pós-graduação em Educação e professor Adjunto III da Pontifícia Universidade Católica de Minas Gerais. Professor de Ensino Técnico e Profissional do CEFETMG. E-mail: $<j w c o s t a 01 @ g m a i l . c o m>$.

${ }^{2}$ Professora da Graduação e da Pós-Graduação da Pontifícia Universidade Católica de Minas Gerais - PUC Minas. E-mail: <lenisemro@gmail.com>.
} 


\section{INTRODUÇÃO}

A Zona de Desenvolvimento Proximal (ZDP) (VIGOTSKY, 1987) configura-se como uma prática de mediação, um espaço de intervenção pedagógica na perspectiva do conhecimento socialmente construído. Com o objetivo de identificar pesquisas que abordam a ZDP no contexto escolar, principalmente nas atividades pedagógicas da Educação a Distância (EaD), este artigo apresenta o levantamento das teses e dissertações publicadas entre 1990 e 2016. Buscou-se identificar os trabalhos sobre as práticas pedagógicas que utilizam como princípio norteador a Zona de Desenvolvimento Proximal (ZDP) de Vygotsky nas interações educacionais. Por meio deste estudo, foi possível elaborar um quadro com os principais eixos das pesquisas produzidas. Para se chegar ao resultado foram utilizados dois descritores que serviram de referência para selecionar os trabalhos. Tendo por base as informações levantadas, pretende-se apresentar os aspectos mais relevantes da pesquisa apontando suas limitações e fragilidades.

A produção de pesquisas em determinada área do conhecimento é importante porque ajuda a identificar teoria, práticas e metodologia dominantes e põe em destaque importantes aspectos do objeto de estudo. Nota-se, quase sempre, nas entrelinhas das pesquisas, um movimento de ruptura ou de continuidade com as concepções teóricas que fundamentam os conhecimentos produzidos, permitindo compreender seus avanços e perceber como essa dinâmica vai constituindo a ciência e revelando as inúmeras possibilidades de produção de conhecimento.

O artigo está estruturado em três tópicos: apresenta-se inicialmente a demanda da pesquisa; em seguida, abordam-se as práticas interacionistas presencial e a distância on-line; e, por fim, procede-se a descrição dos dados levantados.

\section{O INÍCIO DA PESQUISA E O MÉTODO}

O interesse pela pesquisa nasceu da necessidade de se conhecer em qual campo as práticas pedagógicas de natureza interacionistas estavam localizadas. Assim, em primeiro momento, definiu-se por realizá-la em bases de dados reconhecidas pela comunidade acadêmica, buscando teses e dissertações que tivessem como princípio norteador a aplicação da Zona de Desenvolvimento Proximal nas práticas pedagógicas. Para que fosse possível compilar os registros levantados, optou-se por adotar a pesquisa exploratória, que para Demo (2000) frequentemente promove a descoberta de enfoques, percepções e terminologias que contribuem para que o próprio modo de pensar do pesquisador seja modificado.

Inicialmente, foi realizada a seleção das bases de dados a serem utilizadas na pesquisa, tendo como critério a escolha de bases nacionais das principais universidades do País - federais, estaduais e particulares - assim como a base de dados da CAPES. A princípio, pode parecer redundante utilizar a base CAPES e também a das universidades, mas os resultados de pesquisa exploratória inicial apontaram que a base CAPES ainda não contempla toda a produção de teses e dissertações do País. Em seguida, foram definidos quais seriam os descritores de busca, ou seja, as palavras-chave e alguns critérios de escolha, tais como o ano de publicação e os programas de pós-graduação que entrariam na seleção dos trabalhos. 
No segundo momento, iniciaram-se as buscas dos trabalhos, fazendo-se a seleção das teses e dissertações a partir da leitura dos resumos e identificando-se se a pesquisa desenvolvida tinha como referência a aplicação da Zona de Desenvolvimento Proximal nas relações de interação no ambiente educacional. Optou-se por selecionar todos os trabalhos identificados, tanto os que foram desenvolvidos no contexto presencial quanto os de ambiente on-line, com o intuito de comparação entre os tipos de trabalhos publicados.

Todas as teses e dissertações selecionadas foram catalogadas em planilha eletrônica, com o registro do nome do autor, do orientador do trabalho, do ano de publicação, da universidade onde o trabalho foi desenvolvido, do programa de pós-graduação, do resumo e do link para o trabalho completo.

A última etapa consistiu na análise dos dados levantados e catalogados que consideraram a aplicação do conceito de zona de desenvolvimento proximal nas interações e experiências educativas no Brasil, nas últimas décadas.

\section{AS PRÁtICAS PEDAGÓGICAS NA PERSPECTIVA INTERACIONISTA}

As práticas pedagógicas utilizadas por professores sempre foram objeto de estudo dos pesquisadores que se interessam por conhecer melhor a realidade escolar e produzir conhecimentos que possam contribuir com as metodologias adotadas pelos docentes. A prática interacionista escolar consta em muitas propostas pedagógicas, mas nem sempre sua ênfase é colocada no processo sócio-histórico dos estudantes. Esse fato tem despertado o interesse dos educadores, que buscam, na pesquisa, uma forma de compreender a teoria interacionista e seus impactos na prática pedagógica dos professores. Percebe-se também que as pesquisas estimulam o interesse sobre a apropriação dessa teoria pela sala de aula a partir das necessidades dos estudantes e sua contribuição na mudança da prática pedagógica escolar.

O estudo de Vygotsky põe ênfase no aspecto interacionista, pois considera que é no plano intersubjetivo, na troca entre as pessoas, que as funções mentais superiores têm origem. Ele defendia a ideia de que o desenvolvimento cognitivo completo requer interação social e que o desenvolvimento começa entre as pessoas como um processo interpsicológico e, em seguida, cognitivamente como um processo intrapsíquico. Vygotsky destaca o intenso efeito da interação social, da linguagem e da cultura sobre o processo de aprendizagem e afirma que a linguagem e o contexto social são instrumentos que potencializam a Zona de Desenvolvimento Proximal (VYGOTSKY, 1987).

No caso da educação escolar, é necessário que o professor conceba, prepare e coloque em prática tarefas de ensino-aprendizagem que potencializem as condições dos sujeitos envolvidos nesse processo. Sob a perspectiva vigotskiana, essas tarefas acontecem por meio da interação entre os sujeitos e da ação intencional do professor, que coloca em destaque o trabalho coletivo. A interação entre os sujeitos acontece de forma autêntica e o professor tem a oportunidade de utilizar diferentes recursos para esclarecer, confirmar e questionar os estudantes, articulando seus sentimentos, suas reflexões e desenvolvendo suas funções cognitivas. Entende-se que na medida em que o homem percebe o seu contexto, reflete criticamente sobre ele e participa ativamente da construção da sua realidade, transforma os processos interpsíquicos em intrapsíquicos. 
Vygotsky ressaltou que o nível de habilidade cognitiva que pode ser desenvolvida com a orientação de adultos ou em colaboração entre pares excede o que pode ser obtido sozinho (KEARSLEY, 2001). Para Vygotsky, as habilidades cognitivas e as formas de estruturar o pensamento não são determinadas por fatores congênitos, mas são resultado das atividades praticadas em conformidade com os hábitos sociais da cultura em que o sujeito se desenvolve. $O$ autor afirma que esse processo é fundamental para a interiorização do conhecimento, isto é, para a transformação dos conceitos espontâneos em científicos (VYGOTSKY, 1987).

A teoria histórico-cultural de Vygotsky apresenta as funções psicológicas superiores como uma construção social que encontra na mediação semiótica um conceito importante, correspondente à intervenção de um terceiro elemento para possibilitar a interação entre dois termos de uma relação. O termo mediação é utilizado por Vygotsky para se referir aos sistemas de signos e ao papel que eles desempenham nas relações do homem com o seu contexto social. Ele explica que os seres humanos criam continuamente instrumentos e sistemas de signos usados para conhecer e transformar o mundo, ao mesmo tempo em que por eles são transformados. (OLIVEIRA, 1993). A perspectiva da mediação evidencia a prática social no contexto das relações para a aprendizagem.

Vygotsky reconheceu um momento de desenvolvimento em que o caráter individual do sujeito é afirmado e o diálogo central para a aprendizagem torna-se discreto e não apenas comum. Para ele, a aprendizagem ocorre por meio da socialização e do esforço individual. Esta maneira de conceber a aprendizagem altera papéis e funções das pessoas envolvidas que precisam incorporar novas formas de fazer educação. No caso dos ambientes educacionais, os estudantes devem ser encorajados a assumir um papel autônomo e ativo na aprendizagem, e é de grande importância sob esse ponto de vista o desenvolvimento de habilidades de estudo, de disciplina para o trabalho independente e individual.

Outro aspecto que tem estimulado a curiosidade dos pesquisadores é o momento atual de uma sociedade com acelerado progresso tecnológico, o que vem suscitando investigações para compreender como a prática pedagógica pode se beneficiar das inovações e promover melhorias no processo ensino-aprendizagem. Segundo Costa e Paim (2004, p. 7) a "utilização de sofisticadas tecnologias na escola requer o desenvolvimento de projetos educacionais bem definidos, que tenham em vista estratégias que ampliem as chances de aprendizagem e conhecimento dos alunos".

Estudiosos como Manuel Castells e Pierre Levy comungam da ideia de que a tecnologia está intimamente imbricada na sociedade e que ela tem sido percebida de diferentes maneiras em cada período histórico. Para eles, a separação entre tecnologia e sociedade, no que diz respeito a cultura, sociedade e técnica, dá-se, apenas, em termos conceituais. Nesse sentido, Castells (2005) afirma que a tecnologia não determina a sociedade, mas é ela que dá forma a necessidades, valores e interesses das pessoas que as utilizam. Para esse sociólogo espanhol, os grandes avanços tecnológicos promovidos no século XX e que foram vivenciados pela humanidade ao longo dos anos, organizam-se ao redor das tecnologias da informação e da comunicação. O autor afirma que o fenômeno provocado pelas tecnologias no comportamento da sociedade contemporânea, conhecido como Revolução Digital, pode ser comparado com a Revolução Industrial, pois da mesma forma trouxe significativas e irreversíveis mudanças nos paradigmas sociais, econômicos, culturais e 
educacionais, como ocorreu com a sociedade do século XVIII. A Revolução Digital do Século XX mudou definitivamente os padrões de comportamento e a forma de pensar e viver no mundo contemporâneo. Ressalta-se que essa revolução ainda não terminou e não tem previsão de final, seus efeitos se ampliam diariamente em um contexto de inovação disruptiva. E os reflexos nos processos educativos e sociais vêm impactando a realidade escolar permanentemente, demandando uma atenção especial dos atores que atuam tanto na área de gestão escolar quanto pedagógica. Uma atenção especial sobre as práticas pedagógicas adotadas pelos professores se torna cada vez mais necessária no sentido de superar práticas tradicionais que não incorporam concepções de conhecimento interacionistas.

As pesquisas nacionais realizadas em diferentes áreas do conhecimento revelam o interesse da comunidade científica em compreender os impactos promovidos pelas tecnologias digitais na educação escolar, trazendo ainda mais questionamentos e ampliando o campo investigativo. A partir do interesse em conhecer e em contribuir com os estudos brasileiros, propõe-se esta pesquisa exploratória sobre as práticas pedagógicas da educação presencial e a distância on-line que utilizam como princípio norteador a Zona de Desenvolvimento Proximal (ZDP) de Vygotsky nas interações educacionais.

Moore (1991) considera que a educação a distância seja a causa e consequência de mudanças significativas na compreensão do que é a educação e da forma como ela deve ser organizada. Peters (2004) esclarece que seu formato de ensinoaprendizagem é indefinido e não fixo, o qual sempre esteve em permanente estado de transição desde a sua origem, há cerca de 200 anos, quando foram criados os cursos por correspondência. Sendo assim, compreende-se que o dinamismo da educação a distância sempre esteve fortemente relacionado com as diferentes tecnologias da informação que foram surgindo ao longo do tempo e das melhorias dos processos de comunicação que foram sendo implementados, desencadeando frequentes atualizações e, consequentemente, novos e mais modernos recursos.

No caso da educação a distância, as inovações estão acontecendo de forma tão rápida e intensa que Peters (2001) aponta que já existem pelo menos três gerações de educação a distância que podem ser identificadas pelo nível de desenvolvimento dos meios e das técnicas para se alcançar as metas do ensino. As tecnologias têm proporcionado cada vez mais a melhoria da comunicação e interação entre os atores do processo de aprendizagem. Alunos, professores e tutores vivenciam a presença virtual e se deslocam nos ambientes virtuais de aprendizagem de forma síncrona e não síncrona e, nessa medida, constroem a cultura da virtualidade através de interações.

O filósofo francês, Pierre Levy (1996), considera as tecnologias como produtos de uma sociedade e de uma cultura. Neste sentido, ele afirma que a distinção entre a cultura, a qual considera como a dinâmica das representações, a sociedade, constituídas das pessoas, seus vínculos, suas trocas, suas relações de força, e a técnica, artefatos eficazes, deve ficar no campo conceitual. Por esse viés, as verdadeiras relações não se estabelecem entre a tecnologia e a cultura, mas entre uma multidão de agentes humanos que inventam, produzem, utilizam e interpretam diversamente as técnicas (LÉVY, 1996). Ou seja, para ele a tecnologia expressa toda a dinamicidade de uma sociedade para impulsionar seu domínio e acompanhar o processo histórico, pois é fruto do trabalho humano. É, portanto, o protagonismo humano que rege as relações 
nos ambientes virtuais, que incorporam todos os seus modos de ser e viver, num processo anunciado por Levy (1996) como dinâmica de fluxo, de movimento, de ir e vir.

No Brasil, o cenário da educação a distância começou a mudar apenas nos anos 90 do século XX com a Lei de Diretrizes e Bases da Educação Nacional (LDBEN 9.394/96), a qual apontou no artigo 80 a educação a distância como campo em desenvolvimento e que demandava investigações sobre suas práticas pedagógicas. Além disso, os marcos legais instituídos a partir da LDBEN têm permitido a EaD nos diversos níveis de ensino, mais fortemente no ensino superior e no ensino técnico.

Moore e Kearsley (1996) apontam as diferenças entre os programas oferecidos e destacam, dependendo dos níveis de extensões, que surgem três variáveis: i) a forma de estruturação do programa; ii) do nível do diálogo estabelecido entre docentes e discentes; e iii) além das características individuais de cada estudante. Os autores destacam ainda que a educação a distância on-line é marcada por diferenças significativas na sua forma de realização, organização estrutural e oferta. Para esses autores, o diálogo entre professor-tutor e o estudante pode ser alcançado com as tecnologias disponíveis, tais como programas de multimídias, livros, palestras em vídeo, um estudo de caso, um fórum de discussão ou outros artefatos. Porém é importante que tanto professores quanto estudantes aprendam a usá-los na Zona de Desenvolvimento Proximal (ZDP), proposto por Vygotsky, pois essas tecnologias fornecem estímulos sociais necessários e importantes para o aprendizado, permitindo ao "professor transitar com facilidade em seu papel de mediador no acompanhamento das interações com e entre os alunos, condições essas fundamentais para um trabalho educativo" (COSTA, MOREIRA e OLIVEIRA, 2004, p. 68) na perspectiva da ZDP.

Acredita-se que seja necessário e prudente considerar os desafios que se apresentam e que revelam a complexidade em torno da educação a distância on-line, bem como as suas controvérsias, tendo em vista que ela é realizada a partir de diferentes padrões e expectativas. E sendo assim, é preciso partir do pressuposto de que a educação a distância, assim como qualquer proposta educativa, requer planejamento pedagógico dentro de concepções modernas do conhecimento; e que, além disso, tendo em vista a sua realização nos ambientes virtuais on-line, requer técnicas e estratégias especiais, instrução e métodos específicos de comunicação, atualização tecnológica constante, formação de professores e tutores permanente, bem como arranjos organizacionais e administrativos próprios para a prática pedagógica.

\section{DESCRIÇÃo dA COLETA DE dADOS E ANÁLISE dOS RESULTADOS}

Para a realização da coleta de dados foram necessários aproximadamente dez meses consecutivos de buscas em bases de dados, filtragem dos trabalhos, leitura dos resumos e seleção de teses e dissertações que estavam em consonância com o objetivo do trabalho. Toda a pesquisa se desenvolveu em bases de dados disponíveis na Web.

Como apontado anteriormente, estabeleceram-se alguns critérios para que a busca fosse realizada, a fim de facilitar o desenvolvimento do trabalho e a organização das ações. Optou-se por iniciar a busca nas bases que abrangessem trabalhos de diferentes universidades e que fossem mais generalizadas, como o banco de teses e dissertações da Coordenação de Aperfeiçoamento de Pessoal de Nível Superior 
(CAPES). Em seguida, realizou-se a busca nas bases das universidades federais, posteriormente nas universidades estaduais e por último nas particulares.

Em relação às bases federais, inicialmente foi necessária a identificação das universidades que possuíam repositório próprio disponível na Internet. Das sessenta e três (63) universidades federais identificadas no Brasil através da Web, foram selecionadas quarenta (40) bases de dados, pois algumas universidades não apresentaram repositório disponível na Web. Foram selecionadas duas universidades estaduais, a Universidade de São Paulo (USP) e a Universidade Estadual de Campinas (UniCamp), por se tratarem das duas maiores universidades estaduais do país. Utilizou-se o mesmo critério para se escolher as bases das universidades particulares, optando pela Pontifícia Universidade Católica (PUC), pela Universidade Mackenzie e pela Universidade do Vale do Rio dos Sinos (Unisinos). Ao todo foram cinquenta e quatro (54) bases utilizadas na pesquisa, conforme mostra o quadro 1.

\begin{tabular}{|c|c|c|}
\hline Tipo & Região & Base de Dados \\
\hline \multirow{4}{*}{ Gerais } & \multirow{4}{*}{-} & CAPES-Banco de Teses e Dissertações \\
\hline & & BDTD - Biblioteca Digital Brasileira de Teses e Dissertações \\
\hline & & FAPESP - Fundação de Amparo a Pesquisa do Estado de SP \\
\hline & & Domínio Público \\
\hline \multirow{26}{*}{ Federais } & \multirow{5}{*}{ Norte } & UFPA - Universidade Federal do Pará \\
\hline & & UNIR-Universidade Federal de Rondônia \\
\hline & & UFT-Universidade Federal do Tocantins \\
\hline & & UFAM - Universidade Federal do Amazonas \\
\hline & & UNIFAP - Universidade Federal do Amapá \\
\hline & \multirow{8}{*}{ Nordeste } & UFPE-Universidade Federal de Pemambuco \\
\hline & & UFPB - Universidade Federal da Paraíba \\
\hline & & UFAL-Universidade Federal de Alagoas \\
\hline & & UFS-Universidade Federal de Sergipe \\
\hline & & UFC - Universidade Federal do Ceará \\
\hline & & UFPI-Universidade Federal do Piaú \\
\hline & & UFBA - Universidade Federal da Bahia \\
\hline & & UFRN - Universidade Federal do Rio Grande do Norte \\
\hline & \multirow{5}{*}{ Centro-Oeste } & UNB - Universidade Federal de Brasilia \\
\hline & & UFGD - Universidade Federal de Grande Dourados \\
\hline & & UFG-Universidade Federal de Goiás \\
\hline & & UFMT - Universidade Federal de Mato Grosso \\
\hline & & UFMS - Universidade Federal do Mato Grosso do Sul \\
\hline & \multirow{13}{*}{ Sudeste } & UFRJ-Universidade Federal do Rio de Janeiro \\
\hline & & UFVJ - Universidade Federal do Vale do Jequitinhonha \\
\hline & & UFSJ - Universidade Federal de São João Evangelista \\
\hline & & UFL-Universidade Federal de Lavras \\
\hline & & UFABC-Universidade Federal do ABC \\
\hline & & UFF-Universidade Federal Fuminense \\
\hline & & UNIFEI - Universidade Federal de Itajubá \\
\hline & & UFJF-Universidade Federal de Juiz de Fora \\
\hline \multirow{14}{*}{ Federais } & & UFOP - Universidade Federal de Ouro Preto \\
\hline & & UFU-Universidade Federal de Uberlândia \\
\hline & & UFES - Universidade Federal do Espínto Santo \\
\hline & & UNIFESP - Universidade Federal do Estado de São Paulo \\
\hline & & UFMG - Universidade Federal de Minas Gerais \\
\hline & \multirow{9}{*}{ Sul } & UNILA - Universidade Federal da Integração Latino-Americana \\
\hline & & UNIPAMPA - Universidade Federal do Pampa \\
\hline & & UFPel -Universidade Federal de Pelotas \\
\hline & & UFRG - Universidade Federal do Rio Grande \\
\hline & & UTFPR-Universidade Tecnológica Federal do Paraná \\
\hline & & UFSM - Universidade Federal Santa Maria \\
\hline & & UFPR-Universidade do Paraná \\
\hline & & UFRGS-Universidade Federal do Rio Grande do Sul \\
\hline & & UFSC - Universidade Federal de Santa Catarina \\
\hline \multirow{2}{*}{ Estaduais } & \multirow{2}{*}{ - } & Unicamp-Universidade Estadual de Campinas \\
\hline & & USP - Universidade de São Paulo \\
\hline \multirow{8}{*}{ Particulares } & \multirow{8}{*}{-} & PUC SP-Pontifícia Universidade Católica de São Paulo \\
\hline & & PUC RS - Pontifícia Universidade Católica do Rio Grande do Sul \\
\hline & & PUC Campinas - Pontifícia Universidade Católica de Campinas \\
\hline & & PUC PR - Pontifícia Universidade Católica do Paraná \\
\hline & & PUC RJ - Pontifícia Universidade Católica do Rio de Janeiro \\
\hline & & PUC MG - Pontifícia Universidade Católica de Minas Gerais \\
\hline & & Universidade Mackenzie \\
\hline & & Unisinos - Universidade do Vale do Rio dos Sinos \\
\hline
\end{tabular}


O descritor principal de busca foi "zona de desenvolvimento proximal" ou "ZDP". Optouse por selecionar apenas teses e dissertações que fossem datadas de 1990 até 2016, abrangendo todos os programas de Pós-Graduação de todas as áreas. O objetivo dessa busca seria o de selecionar trabalhos com experiências de práticas pedagógicas tanto em sala de aula quanto em ambientes virtuais de aprendizagem que tivessem 0 conceito de zona de desenvolvimento proximal como referência.

De forma geral, as bases de dados das universidades federais utilizavam o mesmo servidor de busca, porém cada base filtrava os resultados de uma maneira diferente. Em algumas foi possível realizar a busca pelo descritor tanto no resumo do trabalho quanto no texto completo, o que tornava os resultados mais refinados e precisos. Porém, em outras bases, isso não foi possível e a busca por meio dos filtros apresentava apenas as opções por título, autor, assunto e ano. Essa foi uma das dificuldades para a realização da busca por filtros, uma vez que eles variavam de base para base e pelo fato de o descritor utilizado, na maioria das vezes, estar presente apenas no corpo do texto ou no resumo ou no título.

Nas bases federais foi possível fazer a busca utilizando as aspas no descritor, o que filtrava resultados com o termo completo e não por palavras isoladas, funcionando muito bem como recurso, pois isso selecionava não apenas os trabalhos com o termo "zona de desenvolvimento proximal", mas também assuntos que estavam relacionados ao termo como interação, sócio-histórico, mediação, etc.

Em algumas bases, o uso das aspas refinava a busca de tal forma que não evidenciava nenhum trabalho, nem mesmo aqueles que estavam relacionados ao termo, sendo que o não uso das aspas filtrava quase todos os trabalhos registrados na base, ou seja, a busca caminhava por extremos: ou filtrava todos os trabalhos ou não filtrava nenhum. Nesses casos, a busca foi realizada utilizando-se o termo sem aspas e colocando-se nas opções de busca avançada outros dois termos associados que eram "Vigotski" e "Vygotsky". Nesse tipo de busca, os filtros não eram tão eficientes, o que gerava grande quantidade de trabalhos selecionados. Sendo assim, a seleção e filtragem das teses e dissertações foram feitas de forma mais manual e, a partir da leitura dos resumos, foram sendo identificados os trabalhos que atendiam ao objetivo da investigação.

A pesquisa nas bases estaduais USP e Unicamp foi mais simples e objetiva, pois os filtros eram muito eficientes e automaticamente estabeleciam critérios de busca tanto pelo descritor, em específico, quanto por assuntos relacionados, retornando resultados coerentes.

As bases de dados particulares também apresentaram um sistema de busca simples e eficiente, não sendo necessário utilizar filtros, pois, apenas com o descritor entre aspas, o resultado era preciso e específico.

A base da CAPES também apresentou um sistema de busca eficiente, desde que o termo fosse colocado entre aspas. A dificuldade com o sistema da CAPES foi o fato de a plataforma ter sido atualizada recentemente, de modo que nem todos os trabalhos que foram evidenciados na busca tinham um registro do resumo ou link de acesso à tese ou à dissertação. Outra dificuldade foi o fato de se encontrar disponíveis apenas os trabalhos publicados a partir de 2013, fora desta temporalidade não foi possível obter informações. Algumas teses e dissertações foram localizadas na base de dados da universidade de origem, porém nem todas estavam disponíveis. 
A base do BDTD foi uma das mais precisas e com maior retorno de busca. Os filtros utilizados foram bem precisos e a busca pelo descritor foi realizada de forma mais eficaz, apresentando poucos trabalhos que não atendiam ao que se procurava.

Outra dificuldade a destacar se refere ao registro dos trabalhos completos de algumas teses e dissertações que apresentaram apenas os resumos disponíveis.

De um total de treze mil cento e setenta e quatro (13.174) trabalhos entre teses e dissertações, foram selecionados apenas $6,5 \%$, uma pequena parte, como indica a Figura 1.

Figura1 - Trabalhos selecionados x não selecionados

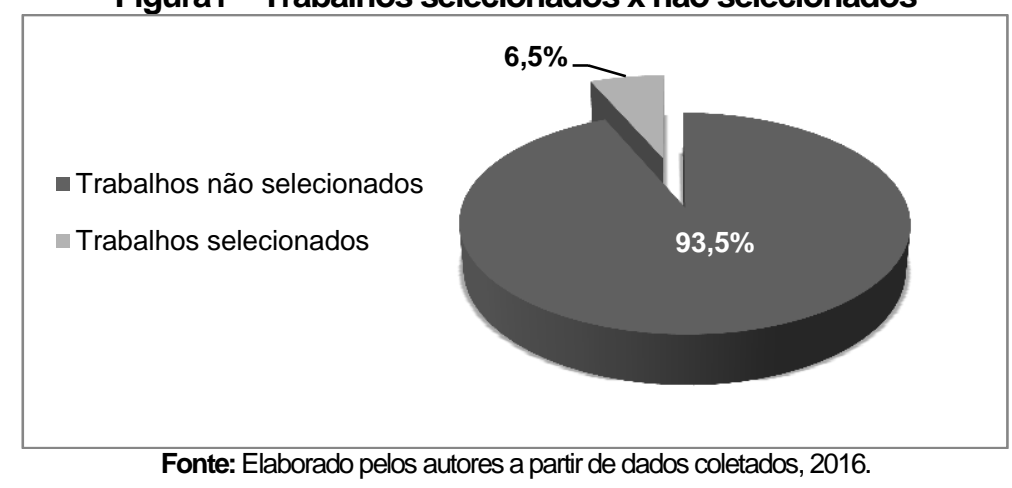

O total de trabalhos selecionados, representados no gráfico, $6,5 \%$, corresponde a um total de oitocentos e cinquenta e dois (852) trabalhos entre teses e dissertações. Todos os trabalhos selecionados respeitavam os critérios estabelecidos na pesquisa e tinham a zona de desenvolvimento proximal como referência do estudo desenvolvido. A figura 2 , a seguir, mostra o percentual de trabalhos selecionados, distribuídos em teses e dissertações.

Figura 2 - Trabalhos selecionados

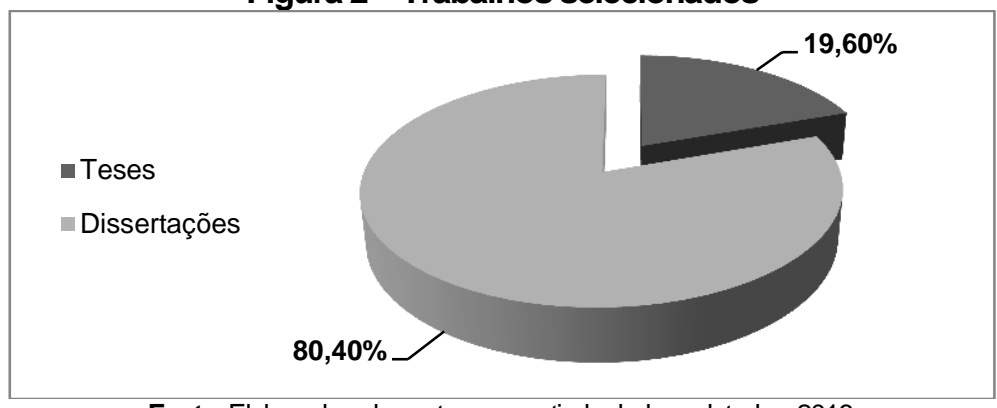

Fonte: Elaborado pelos autores a partir de dados coletados, 2016.

A partir das análises dos resumos das teses e das dissertações, foram identificados quatro eixos principais em que os trabalhos se distribuíam, sendo que esses eixos foram baseados no contexto em que a zona de desenvolvimento proximal foi aplicada, como um norteador para análise das interações e mediações.

O primeiro eixo consistiu nos trabalhos relacionados ao contexto de sala de aula, analisando as interações presenciais entre professor-aluno e aluno-aluno. Este eixo abrangeu tanto teses e dissertações de diferentes níveis de ensino, desde os anos iniciais até o ensino superior, quanto de diversos tipos de conteúdo como matemática, ciências, história e língua portuguesa. 
O segundo eixo se referiu aos trabalhos relacionados ao contexto do uso de tecnologias, em que foram analisadas as interações professor-aluno e aluno-aluno no ambiente presencial da sala de aula, porém mediadas pelo uso de tecnologias como aplicativos e jogos educativos.

O terceiro eixo se referiu aos trabalhos relacionados ao contexto de estudantes com necessidades educacionais especiais, no qual foram analisadas as relações entre professor-aluno e aluno-aluno no ambiente presencial.

O quarto e último eixo se referiu aos trabalhos sobre as relações professor-aluno e aluno-aluno na educação a distância on-line (EaD), a partir de ambientes virtuais de aprendizagem.

Figura3 - Divisão dos trabalhos por eixos

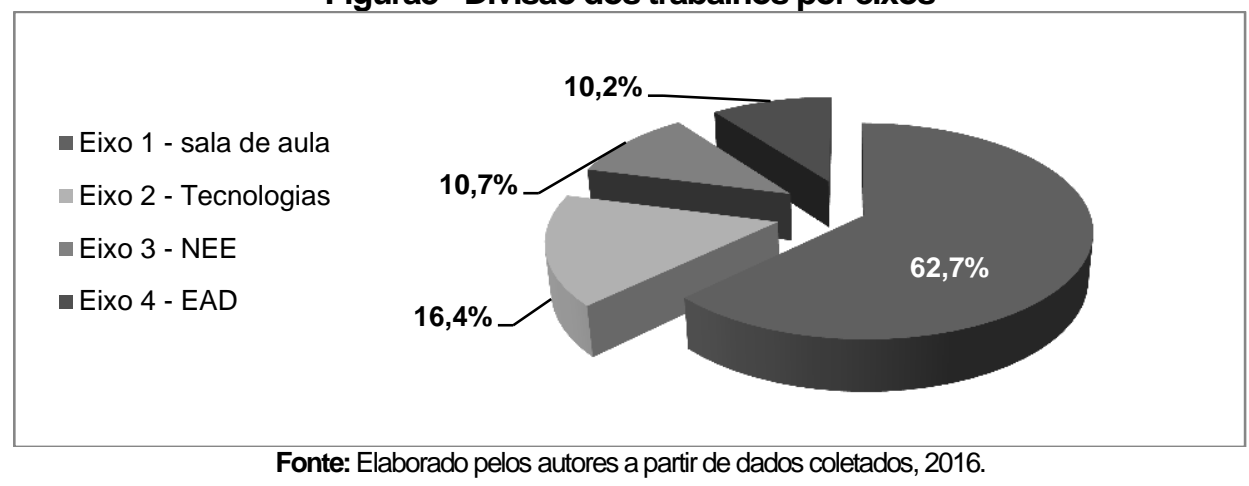

A partir da pesquisa realizada, observou-se (gráfico da figura 3) que número de trabalhos desenvolvidos com base na aplicação da zona de desenvolvimento proximal de Vygotsky na educação presencial correspondeu a $62,7 \%$ do total, sendo substancialmente maior do que aqueles relacionados à educação a distância. Naturalmente, este resultado já era esperado. Os eixos de maiores destaques foram os de estudos sobre a sala de aula, o uso de tecnologias como aplicativos e jogos e o trabalho com estudantes com necessidades educacionais especiais, totalizando a maioria dos trabalhos publicados, $89,8 \%$. Apenas 10,2\%, correspondente a oitenta e sete (87) trabalhos, foram referentes à educação a distância on-line, evidenciando a necessidade de maior investigação nesse campo do conhecimento.

\section{CONSIDERAÇÕES FINAIS}

A proposta desta pesquisa foi delinear o campo das investigações sobre as práticas pedagógicas que têm como princípio norteador a aplicação do conceito de Zona de Desenvolvimento Proximal (ZDP) no ambiente escolar. E tendo como foco principal estudos da mediação vigotiskiana nos ambientes EaD.

A grande maioria dos trabalhos investigados aborda a utilização da ZDP no contexto do ensino presencial com foco nas interações em sala de aula e sem a utilização das tecnologias digitais. Considerando-se o recorte temporal, 1990-2016, a pesquisa da utilização da tecnologia digital na sala de aula no contexto da mediação vigotiskiana tem sido pouco explorada, fato relevante se forem considerados estudos da utilização do computador em sala de aula a partir da década de 70 do século passado. Também foi possível observar poucos estudos sobre a utilização da zona de desenvolvimento proximal nas práticas pedagógicas da educação a distância on-line. Salienta-se, dessa 
forma, a necessidade de pesquisas para se conhecer melhor estes processos de ensino-aprendizagem, tanto aquele que incorpora a tecnologia digital no ambiente presencial, quanto aquele que se desenvolve na modalidade $\mathrm{EaD}$. O vetor tecnológico de desenvolvimento da EaD é muito evidente através das inovações que surgem de forma intensa e disruptiva. Além disso, é fato relevante o crescimento da oferta de cursos oferecidos na modalidade EaD no País na atualidade, o que aponta para a necessidade de ampliar o olhar sobre a teoria interacionista e sobre as relações de ensino-aprendizado promovidas nos ambientes de educação a distância on-line.

Além disso, o ensino híbrido ou blended learning, que mescla atividades de ensino em ambientes presenciais e virtuais a distância, ainda pouco discutido e implementado nas escolas brasileiras, mas que vem vivenciando crescimento substantivo, poderá ser beneficiado por abordagens metodológicas mais apropriadas para uma nova forma de ensinar e aprender.

Este trabalho possibilitou um olhar sobre a dimensão da pesquisa em educação considerando a mediação pedagógica em sala de aula na perspectiva da ZDP. A partir do foco nas pesquisas em relação à modalidade de educação a distância on-line, percebeu-se a construção de olhares sobre o objeto processo de ensinoaprendizagem, mas ainda podendo ser considerada insipiente do ponto de vista numérico e, até mesmo, na perspectiva das especificidades em relação ao objeto de estudo. Há carência de estudos que possam favorecer um melhor entendimento da mediação on-line e, quem sabe, proporcionar novas abordagens pedagógicas que possam favorecer o processo educativo, principalmente para a prática educativa que incorpora os ambientes virtuais e para a educação a distância.

\section{Referências}

BRASIL. Ministério da Educação. LDB - Lei de Diretrizes e Bases da Educação Nacional: Lei n. 9.394, de 1996. Brasília: Senado Federal, Secretaria Especial de Editoração e Publicação, 1997.

BRASIL. Decreto n. 5.622, de 8 de junho de 2005. Regulamentada pela Lei 9.394 de 20 de dezembro de 1996, para dispor sobre a organização do Ensino a Distância. Diário Oficial da União. Brasília, 19 de dezembro de 2005.

CASTELLS, Manuel. A sociedade em rede: do conhecimento à política. In: CARDOSO, Gustavo. A sociedade em rede do conhecimento à acção política. Lisboa: Casa da Moeda, 2005. p. 17-30.

COSTA, J.W.; PAIM, I. Informação e Conhecimento no Processo Educativo. In: COSTA, José Wilson da; OLIVEIRA, Maria Auxiliadora Monteiro (Orgs). Novas linguagens e novas tecnologias: educação e sociabilidade. Petrópolis/RJ: Vozes, 2004.

COSTA, J.W.; Moreira, M., Oliveira, C. C. I. Ambientes Informatizados de Aprendizagem. In: COSTA, José Wilson da; OLIVEIRA, Maria Auxiliadora Monteiro (Orgs). Novas linguagens e novas tecnologias: educação e sociabilidade. Petrópolis/RJ: Vozes, 2004.

DEMO, Pedro. Metodologia do conhecimento científico. São Paulo: Atlas, 2000.

KEARSLEY, G. Social development theory. Retrieved September 19, 2001, from, Theory Into Practice (TIP). Disponível em: <http:/tip. psychology. org/vygotsky.html>. Acesso em: 06 set 2018.

LÉVY, Pierre. O que é virtual? São Paulo: Editora 34, 1996.

MOORE, M. G. Editorial: Distance education theory. The American Journal of Distance Education, 5(3), 1991, p. 1-6.

MOORE, Michael Ghahame; KEARSLEY, Greg. Distance education: a system view. Belmont (USA): Wadsworth Publishing Company, 1996. 
PETERS, O. A educação à distância em transição: tendências e desafios. São Leopoldo: Unisinos, 2004.

PETERS, O. Didática do ensino a distância. São Leopoldo: Unisinos, 2001.

VYGOTSKY, L. S. Thougth and Language. London and Cambridge, MA: The Mit Press. 1987.

Data da submissão: 04/12/2018

Data da aprovação: 21/02/2019 